\title{
Outreach activities on light science and technology at TecnOpto-UMH during the International Year of Light
}

María del Mar Sánchez-López, Pascuala García-Martínez, Rocío Espinosa, Jesús Carnicer, Julia Arias, et al.

María del Mar Sánchez-López, Pascuala García-Martínez, Rocío Espinosa, Jesús Carnicer, Julia Arias, Ignacio Moreno, "Outreach activities on light science and technology at TecnOpto-UMH during the International Year of Light," Proc. SPIE 9946, Optics Education and Outreach IV, 994604 (27 September 2016); doi: 10.1117/12.2237157

SPIE Event: SPIE Optical Engineering + Applications, 2016, San Diego, California, United States 


\title{
Outreach activities on light science and technology at TecnOpto-UMH during the International Year of Light
}

\author{
María del Mar Sánchez-López*a,b, Pascuala García-Martínez ${ }^{\mathrm{c}}$, Rocío Espinosa ${ }^{\mathrm{d}}$, Jesús Carnicer ${ }^{\mathrm{e}}$, \\ Julia Arias ${ }^{\mathrm{d}}$, Ignacio Moreno ${ }^{\mathrm{d}}$ \\ ${ }^{a}$ Instituto de Bioingeniería, Universidad Miguel Hernández, 03202 Elche, Spain

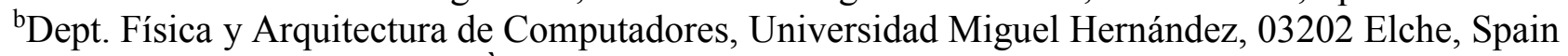 \\ 'Departament d'Òptica, Universitat de València, 45100 Burjassot, Spain \\ ${ }^{\mathrm{d} D e p t . ~ C . ~ M a t e r i a l e s, ~ O ́ p t i c a, ~ T e c . ~ E l e c t r o ́ n i c a, ~ U n i v e r s i d a d ~ M i g u e l ~ H e r n a ́ n d e z, ~} 03202$ Elche, Spain

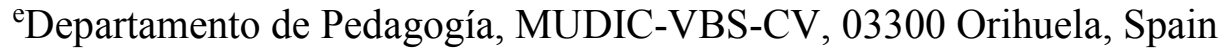

\begin{abstract}
TecnOpto is a group of researchers and teachers with interests in Optics and Photonics, located at the University Miguel Hernández (UMH) of Elche (Spain). Here we report on our outreach activities carried out during the International Year of Light - 2015. They include experiments and demonstrations at elementary and secondary schools, seminars and exhibitions at the university, and the activity named the "Classroom for the Experience", targeted to elder people. We also report on our participation in the science fair in Elche and in the launching of "the Room of Light", a complete new section of the MUDIC science museum devoted to light and optics. MUDIC is located in the UMH campus of Orihuela, and receives visitors from all over the region, mainly young students from elementary and secondary schools. Finally, we report on the exhibition "Women in Light Science and Light Technologies" which was organized by members of our group in collaboration with RSEF - the Spanish Royal Physical Society and SEDOPTICA - the Spanish Optical Society and sponsored by SPIE. This exhibition consisting of twelve posters on relevant women scientists was inaugurated in the XI Spanish Meeting on Optics and has travelled around many universities and cultural centers in Spain. A summary of the contents, participation and developing of all these activities is presented.
\end{abstract}

Keywords: Optics outreach, International Year of Light, Women in Light Science, science fair, optics experiments.

\section{INTRODUCTION}

Last February took place in Mérida (Mexico) the closing ceremony of the International Year of Light (IYL). During the past year a myriad of activities promoting Light science and Light-based technologies have been held worldwide. As one can read in the official report [1] this UNESCO declaration of 2015 as the International Year of Light has been a great success and has certainly fostered the dissemination of Optics and Photonics in our Society and the impact it has in our lives. In Spain we had our national committee for this celebration, which has embraced the organization of many events, seeking funding and support from the authorities [2].

TecnOpto is a group of researchers and teachers located at the University Miguel Hernández (UMH) of Elche (Spain). We develop research and educational projects in Optics and Photonics [3]. As professionals in this field, it was impossible not to be thrilled by this celebration. In this communication we report on the many outreach activities we have carried out during the celebration of the International Year of Light 2015, some of which have been extended to the present year. These activities were each targeted for different kind of publics, from elementary and secondary school students, to university students, to elder people, and also to the general public.

Optics experiments and demonstrations were performed for students at an elementary school, where concepts involving the nature of light, formation of images, color, and different light sources were introduced. Children worked in small groups using material from different kits, like those from SPIE, from OSA, or an optics kit from Photonics Explorer Kit by Eyest [4] containing lenses, mirrors, polarizing films, diffraction gratings and light sources. Outreach seminars within

*mar.sanchez@umh.es

Optics Education and Outreach IV, edited by G. Groot Gregory, Proc. of SPIE Vol. 9946, 994604

(C) 2016 SPIE · CCC code: 0277-786X/16/\$18 - doi: 10.1117/12.2237157 
a conference format and including experimental demonstrations were conducted at two secondary education centers. These hands-on optics activities aimed for kids of elementary and secondary schools are explained in Section 2.

We also review our outreach activities carried out within the university level. A series of seminars and exhibitions were organized in the frame of a winter course, covering different topics related to light science and its applications, including two seminars on the 2014 Nobel Prizes in Physics and Chemistry. Another activity was directed to elder people attending what is called the "Classroom for the Experience", where elder people attend courses at the University, specially designed for them [5]. For these senior students we gave an overview of the different models on the nature of light along history, and the impact of light technologies on everyday life. The objectives and results of these activities are described in Section 3 .

Another kind of activities were designed for the general public and they are described in Section 4. First, we report on the inauguration of a new section named "the Room of Light" in the MUDIC science museum in Orihuela [6]. This new area of the museum is fully devoted to light based experiences. Second, we report on the hands-on experiments in Optics and Photonics that were prepared during the science fair in Elche, which was held in the town Conference Center in April 2015 and in April 2016 [7]. A summary of the contents, participation and success of this activity, partially sponsored by FECYT - the Spanish Foundation of Science and Technology program, is given.

With the aim of raising awareness of the role of women in Optics and Photonics and in order to promote scientific vocations among girls, in Section 5 we report on the exhibition "Women in Light Science and Light Technologies" in whose organization members of our group participated in collaboration with the Spanish Royal Physical Society and the Spanish Optical Society, and which was sponsored by SPIE. This exhibition, consisting of twelve posters, each dedicated to a female scientist in the field of Light, was inaugurated in the XI Spanish Meeting on Optics held in Salamanca last September and has since then travelled around many universities and cultural centers in Spain.

Finally, in section 6, general thoughts about the results and legacy of these activities are provided as conclusions.

\section{HANDS-ON OPTICS ACTIVITIES FOR ELEMENTARY AND HIGH-SCHOOL STUDENTS}

One of the objectives of the IYL-2015 is to increase optics and photonics awareness and promote scientific and professional vocations in this field. Following this target we visited the elementary school C.E.I.P. El Palmeral (Elche) and the two high-schools I.E.S Miguel Hernández (Novelda) and Les Carolines (Valencia). We carried out the activities listed in Table 1 to kids of $2^{\text {nd }}, 4^{\text {th }}$ and $5^{\text {th }}$ grade (elementary school, ages 7,9 , and 10 ) and $1^{\text {st }}$ to $4^{\text {th }}$ year of secondary school (ages 12 to 15). The number of kids and teenagers addressed was 150 and 120 , respectively.

We used the Photonics Explorer Kit by Eyest [4], plus other components like laser pointers, large film polarizers, and holographic googles provided by our colleagues at San Diego State University (SDSU). Photonics Explorer is an educational kit developed by the photonics research team B-PHOT at Vrije Universität Brussels. Since the kit contains ten identical bags of material, the students where set in ten groups of two or three people in every session, and were performing the same experiment simultaneously. Each session began with an introduction to what is light and why the IYL-2015, with contents adapted to the age of the students. The sessions ran in a creative and collaborative environment, giving the students the chance to pose questions, make errors and come up with the best answers in order to foster scientific skills [8]. Research shows that girls lose interest in science at an early age (around age 11) [9], therefore, attention was paid to stimulate the active participation of girls during the sessions at the high-schools.

Table 1 shows the list of experiments that were carried out, including the material used and the main concept that we wanted to convey. First of all, the concept of light is given as what allows us to see, the students try different light sources, and through a simple experiment (handmade pinholes in cards) they understand that light travels in a straight path in air. They are then ready to see that light rays bend when hitting another medium where the speed of light is different than in air, and how this is the base of common optical instruments. The imaging of an object, a magnifying glass and a telescope are built using the plastic lenses in the kit. This leads us to explain how our eyes work and do a funny and simple trick to show our stereoscopic vision using our hand and a hollow tube.

The third block of experiments, which uses off-the-shelf material, turned out to be the most popular among the youngest kids. Because of the almost perfect refractive index match between sunflower oil and pyrex glass $\left(\mathrm{n}_{\mathrm{oil}}=1.46, \mathrm{n}_{\text {pyr }}=1.47\right.$ at $25^{\circ}$ ), optical invisibility is shown: a small pyrex glass filled with oil, and placed inside a larger pyrex glass, "disappears" when the latter is filled with oil. The physical explanation of this effect (the not bending of light) is well understood because the students had experienced in the previous block the refraction of light. This simple experiment conveys the fact that 
many magic tricks have a scientific explanation. Fluorescence of oil is then shown by illuminating it with a laser pointer, and this is used to reveal the presence of the "invisible" inner pyrex glass. Details of the experiment are given in [10]. Fluorescent pens and fluorescent cardboards illuminated with laser pointers of different wavelengths (red, green and violet) were used and (without mentioning photons) the relation between the "color" of light and energy is grasped. Kids write secret messages using "invisible" ink that are later revealed with UV light. All this leads to mention some applications of fluorescence, like in quality control of edible oil, detecting counterfeit bills or as a marker in biology.

\begin{tabular}{|l|l|l|}
\hline \multicolumn{1}{|c|}{ Experiment } & \multicolumn{1}{|c|}{ Material } & \multicolumn{1}{c|}{ Objective } \\
\hline Light sources & $\begin{array}{l}\text { Light bulbs, lanterns, LEDs, laser } \\
\text { pointer }\end{array}$ & $\begin{array}{l}\text { What is Light and its straight path } \\
\text { travelling }\end{array}$ \\
\hline $\begin{array}{l}\text { Optical instruments } \\
\text { (magnifying lens, } \\
\text { telescope) and optical } \\
\text { fiber }\end{array}$ & $\begin{array}{l}\text { Glass of water, Lenses (convergent } \\
\text { and divergent), mirrors (flat, convex } \\
\text { and concave), hollow paper tube, } \\
\text { plastic optical fiber }\end{array}$ & $\begin{array}{l}\text { The trajectory of light can be } \\
\text { deviated for specific purposes } \\
\text { (image formation, 3D real image, } \\
\text { guiding light). How our eyes work. }\end{array}$ \\
\hline $\begin{array}{l}\text { Optical } \\
\text { invisibility/Fluorescence }\end{array}$ & $\begin{array}{l}\text { Sunflower oil, pyrex recipients (2), } \\
\text { olive oil, laser pointers, fluorescent } \\
\text { pens and cardboards, invisible ink- } \\
\text { pen. }\end{array}$ & It's science, not magic! \\
\hline $\begin{array}{l}\text { St. Martins arch colors } \\
\text { with a slide (diffraction) }\end{array}$ & $\begin{array}{l}\text { Diffraction gratings, lanterns, laser } \\
\text { pointer, hologram googles }\end{array}$ & $\begin{array}{l}\text { Light spectrum/Light is "spread" by } \\
\text { tiny features }\end{array}$ \\
\hline $\begin{array}{l}\text { Polarization and } \\
\text { photoelasticity }\end{array}$ & $\begin{array}{l}\text { Polarizing films, spring, computer } \\
\text { screen, transparent plastic objects, } \\
\text { tongs }\end{array}$ & $\begin{array}{l}\text { Grasping the concept of polarization } \\
\text { and some applications }\end{array}$ \\
\hline Light and Colors & RGB LEDs, convergent lens & $\begin{array}{l}\text { Color mixing: additive combination } \\
\text { versus subtractive combination }\end{array}$ \\
\hline
\end{tabular}

Table 1. List of experiments performed at elementary and secondary schools.

The next set of experiments shows the decomposition of light in colors by using a diffraction grating and a lantern. Attention is driven to the color that deviates the most and the least. Once this is understood, diffraction is shown with a laser pointer and here the idea is conveyed that tiny features "spread" light in specific directions. In the case of high-school students a second laser pointer of different wavelength is used to show that these directions depend on the colour of the laser. The concept of wavelength, its relation with the color of the laser, and the model of light as a wave can be introduced picturing waves in the sea or using a spring. To end this $4^{\text {th }}$ block, the kids put on a pair of googles (courtesy of San Diego State University) with a funny hologram encoded as a further example of how light propagation can be "engineered" and its applications as industrial marking, etc.

In the $5^{\text {th }}$ block of experiments we generate vertical and horizontal oscillations in a spring in order to introduce the concept of polarization of light. After that, the kids play with the plastic polarizers and check how the light transmitted changes intensity depending on the relative orientation of the polarizers. Using the LCD screen of a computer, and placing a polarizer in front of it, they clearly see that the light from the screen is polarized. A plastic object is then put in between the computer screen and the polarizer, revealing a range of colors. By tensing the plastic piece these colors change. We mention that this is used to test points of tension in constructions from their scaled plastic models.

The last set of experiments is devoted to play with the sum of colors with light by using the RGB LEDs and a convergent lens that forms the image of the LED lamp. The concept of primary and secondary colors is given and the difference to the mixing of colors in painting is emphasized. This is a common source of confusion, as there are different sets of primary colors depending on whether we are working with additive (light) or subtracting mixing (paint) and kids are very much familiar with the latter. Figure 1 shows photographs taken during these activities, which were mentioned in the July 2016 news release of ICO [11].

Although the IYL had come to an end, this year we continued these hand-on optics activities during "Les Jornades de la Llum" (The days of Light) at CEIP El Palmeral, but we introduced an interesting change: since the kids that were now in 
$6^{\text {th }}$ grade had made the experiments in the previous year, some were selected as assistants to guide their younger school mates into the set of experiments. Figure 2 shows the picture of these six boys and girls who did a great job!
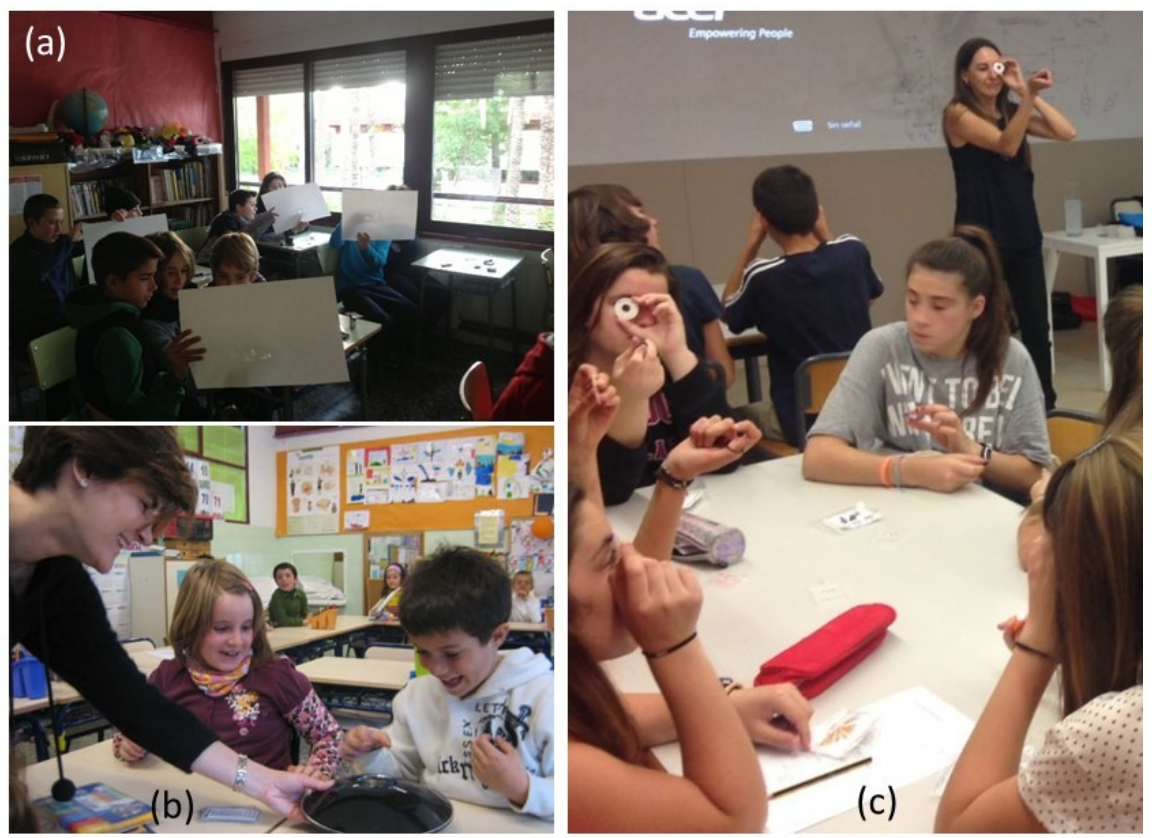

Figure 1. Optics experiments by 5 th grade kids (a) and $2^{\text {nd }}$ grade kids (b) at elementary school El Palmeral (Elche, Spain) in February 2015 and teenagers aged 14 in Escola Les Carolines (Valencia, Spain) in May 2016.

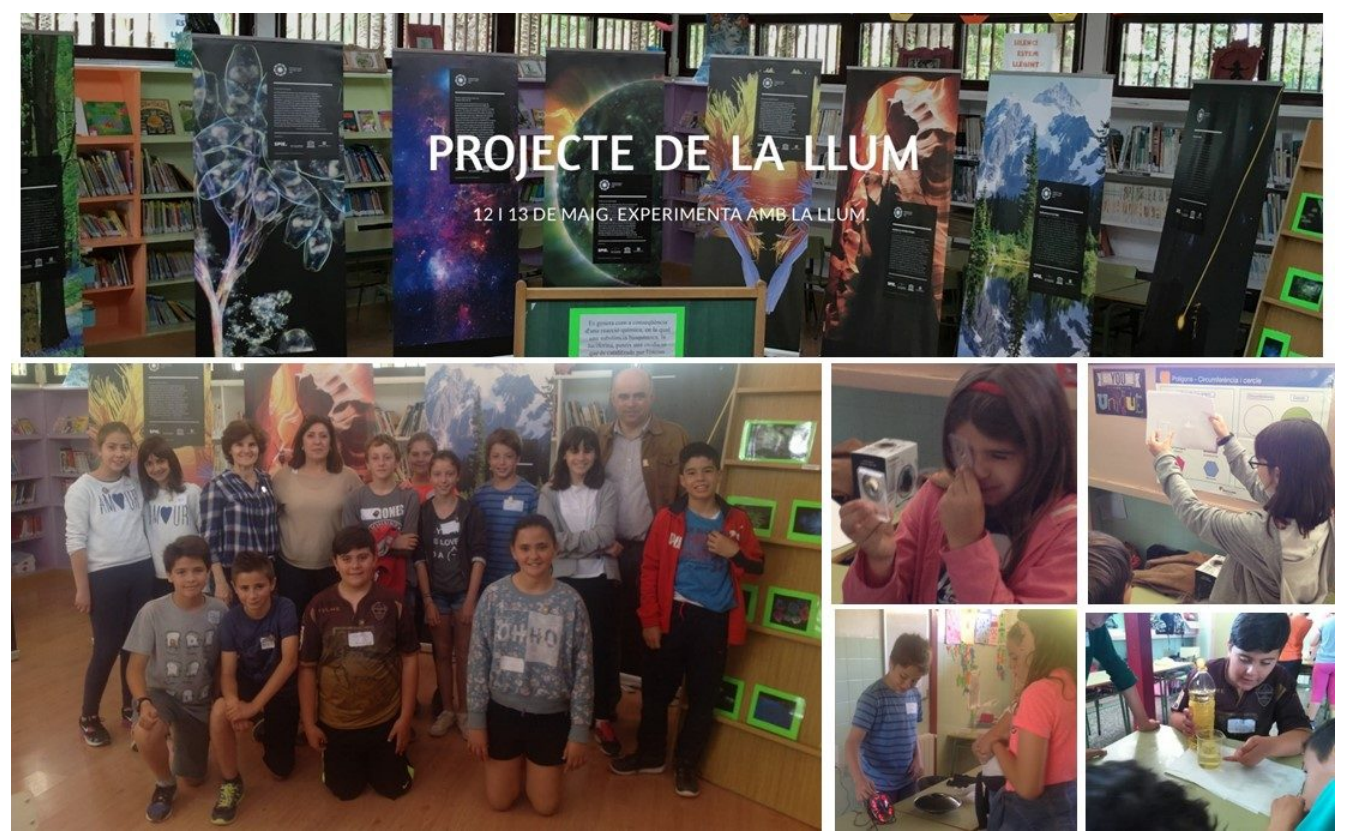

Figure 2. Kids from $6^{\text {th }}$ grade of elementary school El Palmeral (Elche, Spain) who helped their mates in the experiments during "Les Jornades de la Llum" in May 2016 [12], with teacher coordinator of the workshop, M.S.L and I.M. The background shows posters from the SPIE exhibit "Light beyond the Bulb" [13] that we translated into Spanish. 


\section{SEMINARS ON LIGHT SCIENCE\&APPLICATIONS AT THE UNIVERSITY}

TecnOpto group is part of an innovative education network involving academic staff from three Spanish universities (Universidad de Valencia, Universidad Miguel Hernández and Universidad de Alicante) that develops educational projects in optics and photonics. Our network has put forward educational multimedia tools based on interactive exercises for raytracing practice, video-tutorials and on-line examination test [14]. Besides these tools that answer the demand of university students for online resources in optics, during 2015 we organized a series of seminars for the dissemination of light technologies to university students. We aimed to show the possibilities of optics and photonics as a professional career.

We organized the winter course "Año Internacional de la Luz", consisting of a series of twelve seminars covering a wide range of topics in light science and its applications. These seminars were given, keeping a dissemination level, by professors of Universidad Miguel Hernández who do research in photonics or who use photonic tools. The winter course was organized in four blocks imparted between February and April 2015, each block was devoted to a general topic and consisted of three seminars with a duration of half-an hour. The attendance to the whole course was recognized as ECTS credits (European Credit Transfer System) to the students of UMH.

The flyer of this winter course is shown in Fig. 3. Starting with an introduction to the International Year of Light, the first block of seminars was devoted to the 2014 Nobel Prizes in Physics and in Chemistry: blue LEDs and high-resolution fluorescence microscopy. These talks were delivered, respectively, by Julia Arias and Ángela Sastre.
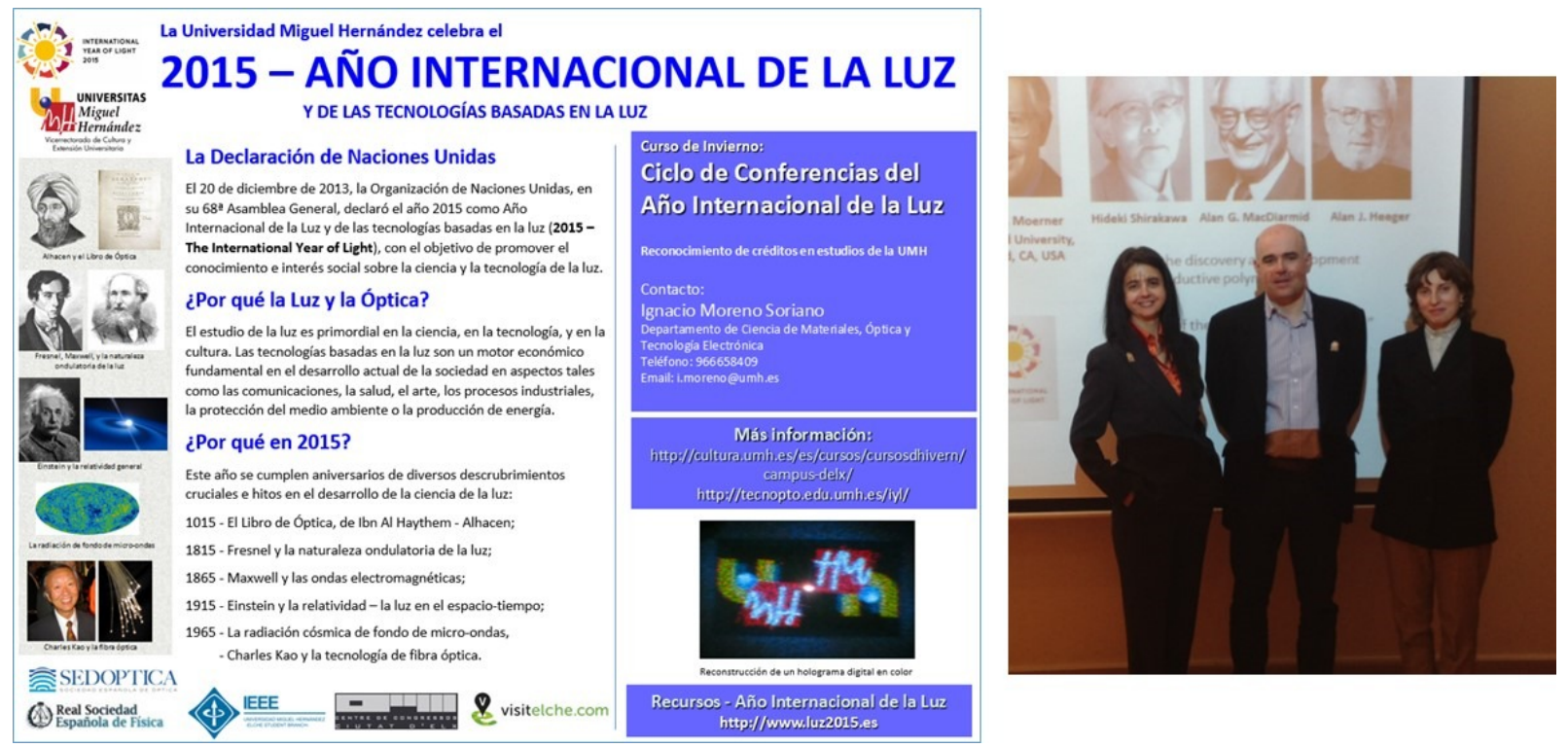

Figure 3. Flyer of the winter course "2015-International year of Light" and photo of the inauguration talks on the 2014 Nobel prize in Physics and in Chemistry, delivered by Julia Arias (right) and Ángela Sastre (left).

The seminars, except the first block which was held at the University, took place at the conference center of Elche and were open to the general public. They were advertised in the local radio and particularly at high-schools. Therefore, the attendees were not only university students who were taking this winter course but also teachers of secondary schools and general public. An average of fifty people was attending each seminar. The whole list of seminars is given below:

- Introduction to the International Year of Light; High-resolution fluorescence microscopy-Nobel Prize in Chemistry 2014; Blue LEDs- Nobel Prize in Physics 2014.

- History and Perspectives of the science of light and its associated Technologies; Lasers: 55 years; Talking with light: optical Communications.

- Light in Biology: History of fluorescence and applications in biology; Light in medicine: from photomedicine to optogenetics; The color of food.

- Light in paintings: Artificial vision: present and future; The energy of light: generation and efficient consumption of luminic energy. 
Another activity for disseminating the role of optics and photonics in our everyday lives targeted elder university students of UMH, belonging to a specially designed course for people over fifty-five called "Aulas UNiversitarias de la EXperiencia" (AUNEX). This one-year course is composed of a number of subjects, aimed at providing general knowledge on humanities, art and science, to elder people who may or may not have attended upper education [5]. Together with these subjects, the course includes a three-hour single-session seminar which changes topic every year. As it could not have been otherwise, the topic of the seminar in 2015 was devoted to the science of light, and the task was offered to our group. Two of the signing authors (M.S.L and I.M) imparted this seminar in the seven university sites that UMH has in the province of Alicante, from March through June 2015.
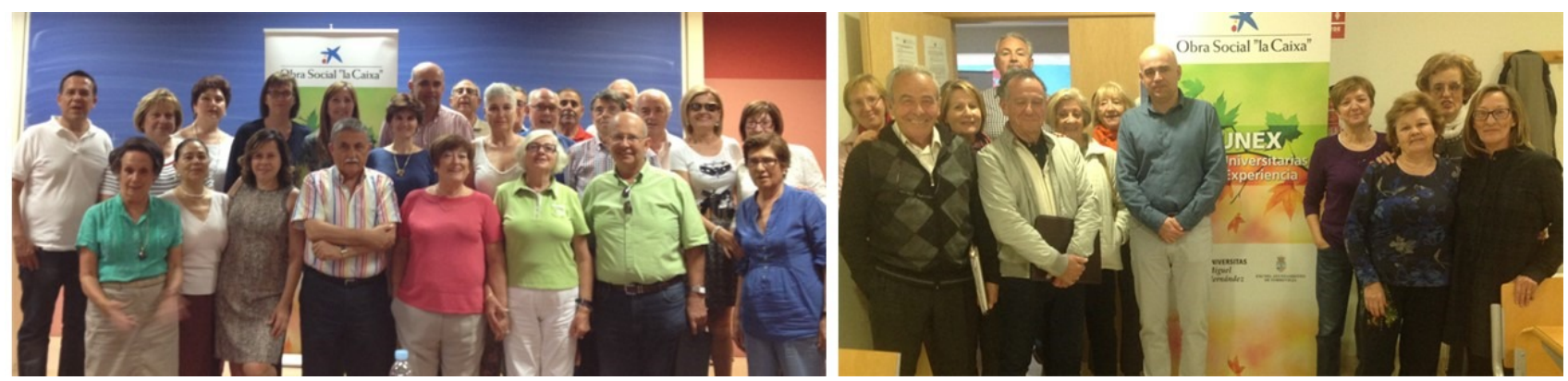

Figure 4. (a) Students participating in the AUNEX seminar of UMH in (a) Orihuela, in (b) Altea in June 2015. These activities were sponsored by Foundation Obra Social la Caixa.

In this seminar we combined a regular dissemination talk with demonstrations and practice session where the audience (about thirty to fifty people) worked in small groups. Once again, the Photonics Explorer kit [4] and additional material from our own class laboratories was used. An overview of the different models of light along history (ray optics, wave model, electromagnetic model, and quantum model) and examples of current applications based on each model were discussed. For each model, we started by introducing the main concepts through slides, then doing real demonstrations, and finishing with hands-on experiments to show the concepts involved. It was a challenging and rewarding experience. It was challenging to explain concepts like interference, diffraction, polarization and basics of lasers to a public with little background in science. Their curiosity and willingness to understand and know more made every session different and very active. Figure (4) shows a picture taken at the end of two of these seminars.

Finally, in May $21^{\text {st }} 2015$ a one-hour dissemination conference entitled "Ottica e Fotonica: la scienza della luce e le tecnologie basate sulla luce" was given by one of the authors (M.S.L) at Università degli Studi di Salerno during the prize ceremony of the XXI Contest in Physics "Eduardo R. Caianiello", organized by the Department of Physics of University of Salerno (Italy) [15].

\section{OUTREACH IN OPTICS FOR THE GENERAL PUBLIC}

We report here on our activities to disseminate optics among the general public. Since fall 2014 and during 2015 members of the group (J.C., R.C, I.M) were deeply engaged in setting up a section of experiments in optics for the Didactic and Interactive University Science Museum in Orihuela (in Spanish MUDIC) [6]. MUDIC is located in the UMH campus in Orihuela, and receives an average of 10,000 visitors per year from all over the region, mainly teachers and students from elementary and secondary schools, and families. Its founding in 2005 was fostered by the association "Hypathia de Alejandría" (composed of a group of high-school teachers leaded by one of the authors, J.C.) with the objective of approaching science to the local society.

The MUDIC museum is organized in six rooms ("salas"), each devoted to a different scientific field and named under a famous scientist: Room Albert Einstein, Room Charles Darwin, Room Henrietta Swan Leavitt, Room Margarita Salas, Room Marie Curie, and the "Room of Light" (or Room Isaac Newton). Two of these sections are brand new and were opened in November 2015: The Room Henrietta Swan Leavitt, devoted to Astronomy, and the Room of Light. This last new section of the MUDIC science museum is entirely devoted to light and optics, and it was supported by an SPIE outreach grant awarded to one of the authors of the present work (I.M). It contains different experiments, including image formation with lenses, polarization of light, optical illusions with mirrors and lenses, a spectrometer using a mobile phone, among other experiments. Thanks to funding from the International Comission for Optics, two Photonics Explorer Kits have been donated to the museum [11]. The inauguration ceremony was presided by the Rector of Universidad Miguel 
Hernández, the mayor of Orihuela and the Director of MUDIC. Ignacio Moreno, as vicepresident of the Spanish Optical Society, delivered the conference focused on the activities of the International Year of Light.

As an example, Figure 5 shows pictures taken during the inauguration ceremony, which included a piece of scientific theater where the characters of Henrietta Swan Leavitt and Isaac Newton discussed about the evolution of science and astronomy. Since the opening, these two areas have been very successful, with continuous visits from schools all over the province and dozens of activities out of the museum, mainly devoted to view astronomical phenomena with the recently acquired telescopes.
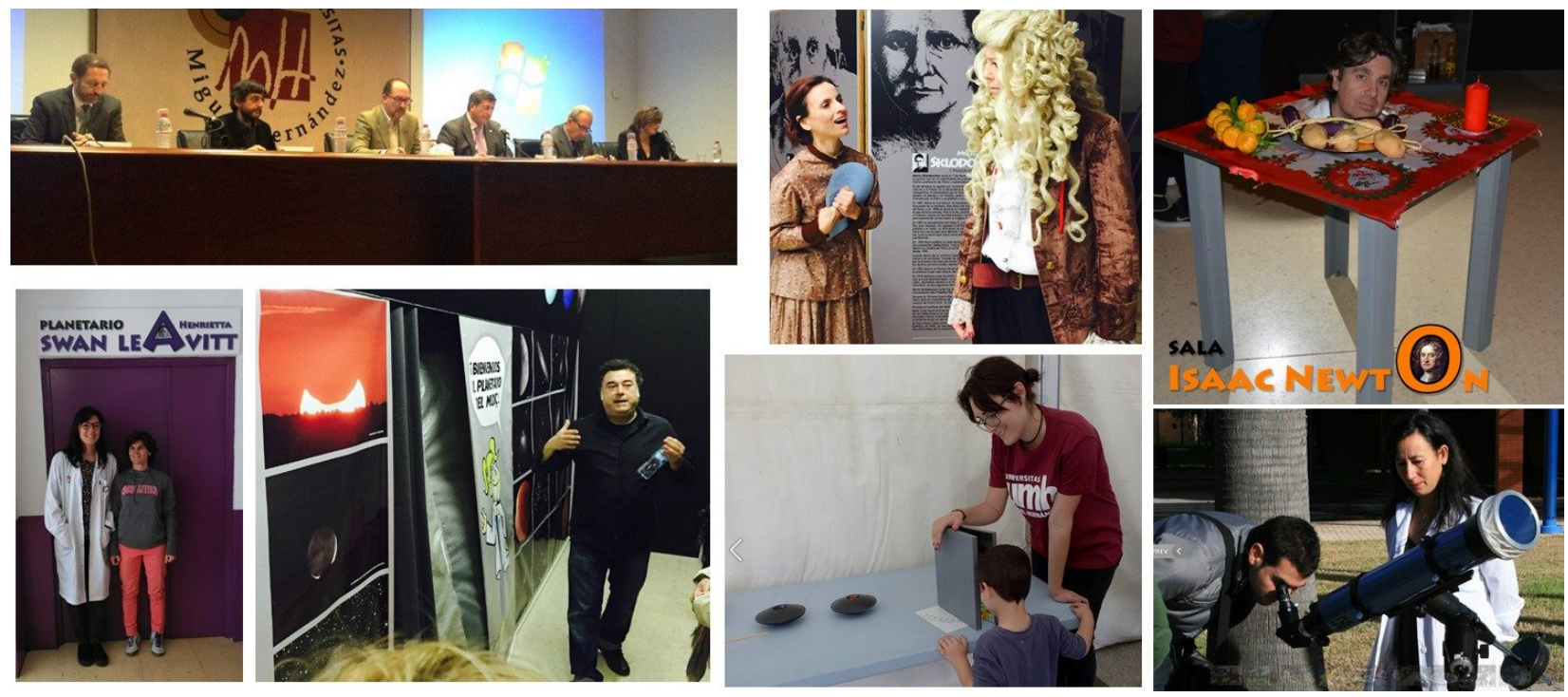

Figure 5. Pictures of the inauguration ceremony of the new rooms at MUDIC, and some of the activities there performed since then.

In April 2015, the $1^{\text {st }}$ urban science fair (FECITELX, FEria de CIencia y TEcnología de Elx) was held in Elche [7]. During three days, the city conference center was hosting exhibitions and about twenty stands, where demonstrations and handson experiments on a myriad of science fields were open to the general public. From DNA obtention to the programming of a robot, more than 20 research groups of UMH participated in this successful event which attracted more than 2000 visitors. Because of the big success of this event, the second edition was celebrated in April 2016. TecnOpto participated in both editions with a stand that included the set of experiments in Table 1, plus additional optical gadgets, like a LEDmessage ventilator and a pressure of radiation bulb. We also organized a laser chess mini contest using the Laser Khet [16]. This game, where players build skills on directing a low-power laser beam toward the contrincant's pieces by means of mirrors and beam splitters shaped in ancient egiptian figures, was a real success. As an example, Figure 6 shows some photographs taken during this science fair.

Thanks to a collaboration between SPIE and the Spanish Optical Society, we had translated into Spanish the posters of the SPIE exhibition Light beyond the Bulb [13], which were exhibited in the $2^{\text {nd }}$ edition of FECITELX [7]. These posters displaying amazing photographs of light-based phenomena have been exhibited too in Universidad Miguel Hernández and in "Les Jornades de la Llum" of the public school El Palmeral in Elche (see Fig. 2 in Section 2), and now belong to the permanent exhibition of MUDIC science museum in Orihuela. It was very rewarding to participate in this city event that brings science closer to the general public, specially families and young people. Thus accomplishing the objective of stimulating curiosity and helping to build scientific vocations. 

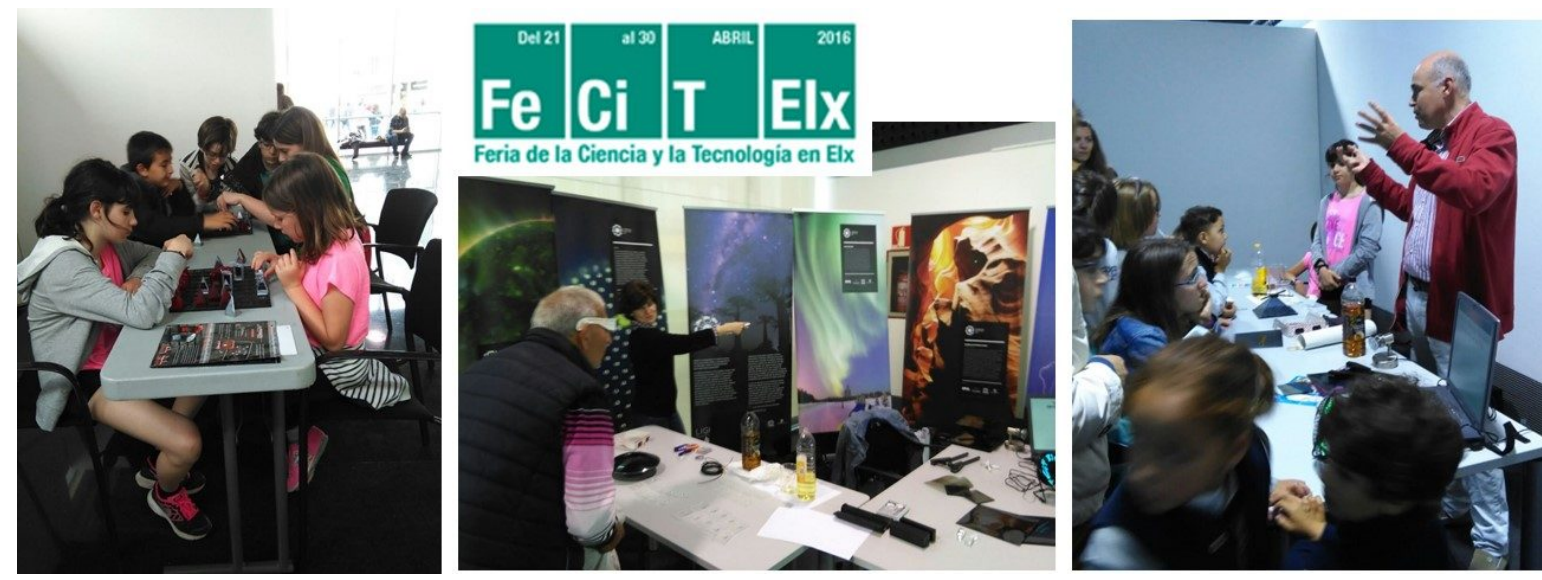

Figure 6. Photos of our stand in the science fair FECITELX showing the Laser Khet contest and hands-on optics experiments.

\section{WOMEN IN LIGHT SCIENCE AND LIGHT TECHNOLOGIES}

One of the objectives that the General Assembly of the United Nations pursued in declaring 2015 the International Year of Light is to "promote the empowering of women in science" and to "stimulate scientific vocations in the field of light and its applications". These were the motivations that guided various members of the Group of Women in Physics belonging to the Spanish Royal Physical Society (RSEF) and of the Spanish Optical Society (SEDOPTICA) to put forward an exhibition to visibilize women who have significantly contributed to the development of light science.

Many are the milestones in the history of light science that are celebrated in 2015, behind each of them stands the name of a scientist: Alhazen, Fresnel, Maxwell, Einstein, Penzias, Wilson and Kao. All men. However, it is absurd to believe that the other half of humanity has been absent in the development of science. Throughout the history of science there have been brilliant and brave women who, despite the odds, have managed to open their way and have illuminated us with their discoveries about light. It was thus the time for us to illuminate them.

Two of the authors signing this communication (P.G.M and M.S.L), have been deeply engaged in this event, the former as the coordinator. As university educators and researchers in optics and photonics, we are very aware of the large gender gap that persists in STEM degrees (Science, Technology, Engineering and Mathematics). Among the many and complex reasons for this situation, the lack of female role models in science and technology is appointed. The twelve female scientists of this exhibit are shown in Fig. (7); a calendar where each of these women leads one month has also been edited in 2016 [17].
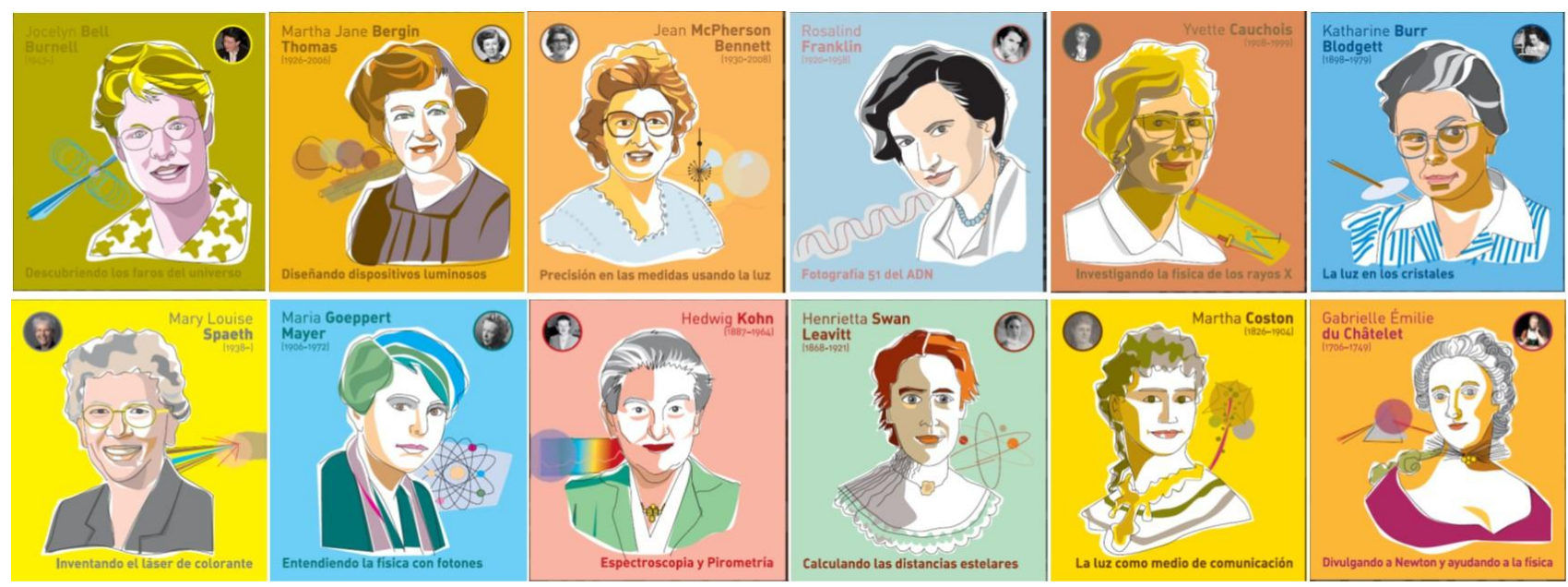

Figure 7. (a) The twelve female scientists of the exhibition "Women in Light and Light Technologies". 
Thanks to the erudition of Gabrielle Émilie Le Tonnelier de Breteuil, known as Madame de Châtelet and her translation into French of the "Principia Mathematica", Newton's theories spread over Europe. Martha Coston was first to develop a communications system for ships based on luminous signals, thus contributing to save many lives. Henrietta Swan Leavitt discovered the method to know the size of our galaxy and the scale of the Universe. Hedwig Kohn's meticulous work in spectrometry and pyrometry are considered as illumination standards. Katherine Burr Blodgett invented the antireflectant glass, whereas Yvette Cauchois created an X-ray spectrograph used to discover new elements of the periodic system. Maria Goppert Mayer, second woman awarded with the Nobel prize in Physics, predicted the two-photon absorption process, and Marie Luise Spaeth invented the tunable dye laser and developed the laser rangefinder. Rosalind Franklin obtained by X-ray diffraction the famous Photo 51, identifying the DNA helical structure. Martha Jane Berghin Thomas was pioneer in lighting research, applying phosphor technology for improving fluorescent tubes, and Jean MacPherson Bennet provided original methods that are a reference in the measuring of optical surfaces. Finally, Jocelyn Bell Burnell discovered the "lights" of the universe: pulsars.

This initiative would not have been possible without the support of the following organizations: the Specialized Group of Women in Physics (GEMF) of RSEF and RSEF itself, SEDOPTICA, SPIE, the Equal Gender Observatory of the University of Valencia (UV), the Institute of Photonic Sciences (ICFO) and the Association of Women in Research and Technology (AMIT). The equal gender observatories of University of Santiago de Compostela and University of Coruña supported financially the realization of a 2016 Calendar based on the exhibit. Also, we would like to acknowledge the invaluable help of Pilar López (President of GEMF), Carmen Carreras (UNED), M ${ }^{\mathrm{a}}$ Josefa Yzuel (UAB), $\mathrm{M}^{\mathrm{a}}$ Luisa Calvo (UCM) and Amparo Pons (UV). The exhibition was launched during the XI Spanish Optical Reunion (RNO), held in Salamanca in September 2015. The coordinator of the exhibit, Pascuala García, shared the inauguration session with the authorities, institution representatives and congress organizing committee, as shown in Fig. 8 (a).
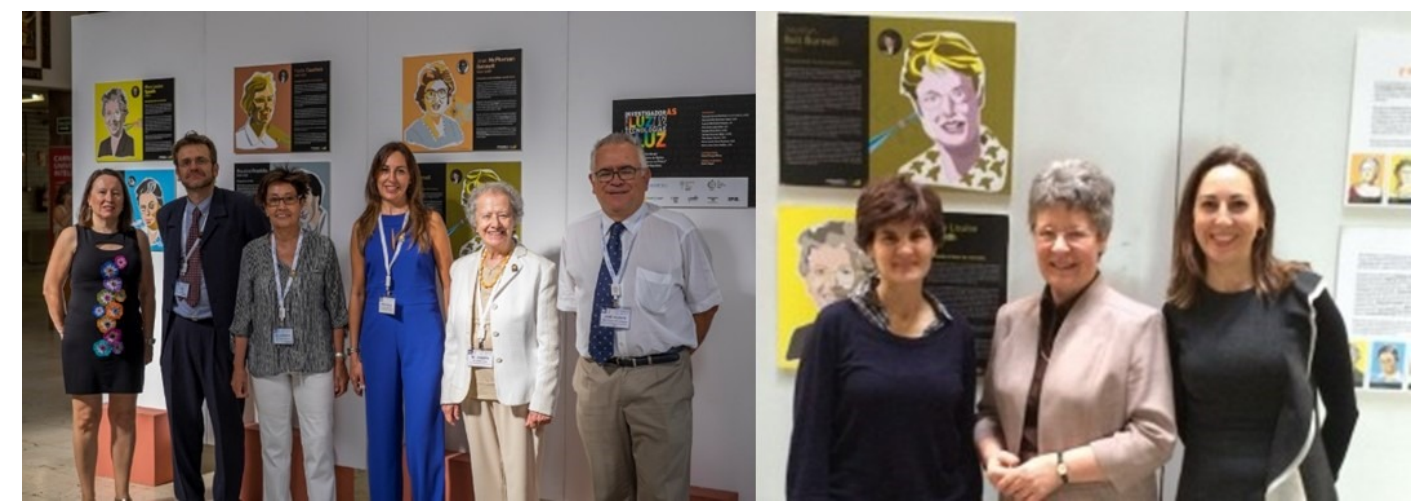

Figure 8. (a) From left to right: Ana J. López (collaborator in the exhibit), Luis Plaja (President of the RNO organizing comittee), Carmen Vázquez (member of the RNO organizing comittee), Pascuala García (coordinator of the exhibit), Ma Josefa Yzuel (President of the Spanish comittee for the IYL) and José Vicente (speaker who delivered the inaugural conference). (b) Jocelyn Bell standing before her panel with Pascuala García and María del Mar Sánchez.

After its launching, the exhibit could be visited in many universities (University of Burgos, Universidad Complutense de Madrid, Universidad Autónoma de Madrid, UNED, University of Alicante, Universidad Miguel Hernández, University of Santiago de Compostela and University of Valencia) and various cultural centers in Spain. As shown in Fig. 8(b), the exhibit at the University of Valencia (UV) coincided with the conference that one of the homage women, the renowned astrophysicist Jocelyn Bell Burnell, delivered on $11^{\text {th }}$ February 2016 within the cycle of seminars organized by the Faculty of Physics. It was a pleasure to meet her on the day when the first detection of gravitational waves was announced. The exhibition continued to be visited during 2016, in science fairs (Pontevedra, Elche), in the townhall of Jaca, in the optometry clinic of UV, and during the "II Jornada de Mujeres en Ciencia e Ingeniería" (II Workshop on Women in Science \& Engineering) organized by Universidad Rey Juan Carlos I (Madrid), where one of the present authors (MSL) delivered a talk promoting optics and photonics as professional career for female students [19].

Scientific societies like SPIE have echoed the exhibition through its journal for members SPIE Professional [20] and its section Women in Optics [21]. It has also been reported in numerous blogs about science, for instance [22] or about women and science [23]. Audiovisual media have served the purpose of its rapid distribution, two videos, in Spanish and English [24], are accessible in Internet thanks to Augusto Beléndez of Universidad de Alicante. 


\section{CONCLUSIONS}

Adapting the words of John Dudley in relation to the global launch of the IYL in Paris: we have had only one International Year of Light and it's been up to us to make the most of it. As educators and researchers in photonics, we have enthusiastically embraced during 2015 the outreach activities here reported. Through experiments devised for elementary and secondary school students, we have aimed to engage young people in hands-on optics and promote curiosity in science and light-based technology. Through the series of seminars delivered at the university, emphasis was put on raising awareness on the problem-solving potential of photonics, in areas like renewable energy, health, technology, and agriculture. The broadest possible cross-section of the public was targeted in the two editions of a local science fair, which bring the opportunity to approach science in a distended and proactive environment. With the hope of creating an on-going interest in optics and photonics a new section devoted to optics experiments, the "Room of Light" was inaugurated in the MUDIC science museum in Orihuela. Last, but not least, we have addressed gender balance in science through the exhibition "Women in Light and light technologies". These women are just a small sample of all the female researchers that have worked, are working and will work in optics and light-based technologies. By highlighting their contributions we expect to have promoted scientific vocations in girls.

Whilst many of these activities have been undertaken on a voluntary basis, we are happy to acknowledge funding from supportive organizations and institutions. These activities have had their echo, reaching out local media through university press releases, radio interviews and, in some cases, local television programs.

\section{ACKNOWLEDGEMENTS}

This work has been financed by Ministerio de Economía y Competitividad (Spain) and FEDER funds through project FIS2015-66328-C3-3-R.

\section{REFERENCES}

[1] Official report IYL-2015 http://www.light2015.org

[2] Spanish Site of the International Year of Light: http://www.luz2015.es/

[3] http://tecnopto.edu.umh.es/

[4] Photonics Explorer Kit by Eyest, http://www.eyest.eu/STEM-Programs/Photonics-Apps

[5] Aulas Universitarias de la Experiencia, Universidad Miguel Hernández: www.sabiex.edu.umh.es/aunex

[6] Museo Didáctico e Interactivo de Ciencias de la Vega Baja MUDIC-VBS-CV: http://www.mudic.es

[7] Feria de Ciencia y Tecnología de Elche: http://fecitelx.umh.es/

[8] Davis, J. M., "Supporting creativity, inclusion and collaborative multi-professional learning," Improving Schools $16,5-20(2013)$.

[9] Baram-Tsabari, A. and Yarden, A., "Quantifying the gender gap in science interests," International Journal of Science and Mathematics Education 9, 523-550 (2010).

[10] Sánchez-López, M. M., Moreno, I., "Optical invisibility by refraction-index matching...but revealed by fluorescence," Opt. Pura Apl. 48, 99-104 (2015).

[11] Vallmitjana, S., “An education legacy of the IYL 2015”, ICO Newsletter No. 108, July 2016.

[12] http://www.facebook.com/amapaelpalmeral/ (posted $15^{\text {th }}$ May 2016)

[13] http://lightexhibit.org/index.html

[14] García-Martínez, P., Zapata-Rodríguez, C. J., Ferreira, C., Fernández, I., Pastor, D., Nasenpour, M., Moreno, I., Sánchez-López, M. M., Espinosa, J., Mas, D. and Miret, J. J., "Innovative Education Networking Aimed at Multimedia Tools for Geometrical Optics Learning,” Proc. SPIE 9793, 97930L 1-7 (2015).

[15] http://www.fisica.unisa.it/PremioCaianiello/PremioERC.asp

[16] Laser Khet 2.0 http://www.khet.com/.

[17] http://www.luz2015.es/documen/1221EMO Calendario web.pdf

[18] http://www.luz2015.es/documen/20150925mujeres.pdf

[19] II Jornadas de Mujeres en Ciencia e Ingeniería www.youtube.com/watch?v=0nZQA-aNKw4

[20] http://spie.org/x115605.xml

[21] http://spie.org/x115422.xml

[22] http://www.agenciasinc.es/Multimedia/Ilustraciones/Doce-mujeres-iluminadas-por-la-luz 
[23] http://mujeresconciencia.com/2015/10/02/exposicion-investigadoras-en-la-luz-y-las-tecnologias-de-la-luz/

[24] https://vimeo.com/135479240 and https://vimeo.com/135466642

Proc. of SPIE Vol. $9946994604-11$

Downloaded From: https://www.spiedigitallibrary.org/conference-proceedings-of-spie on 26 Apr 2023 Terms of Use: https://www.spiedigitallibrary.org/terms-of-use 